\title{
RELATIONSHIP OF BLOOD PRESSURE RESPONSES TO ISOMETRIC EXERCISE IN NON-HYPERTENSIVE MEDICAL STUDENTS WITH FAMILIAL HYPERTENSION
}

\author{
Umema Zafar ${ }^{1}$, Shafiq Ur Rahman ${ }^{1}$, Omar Malik², Henna Salman ${ }^{1}$ \\ ${ }^{1}$ Department of Physiology, Khyber Medical College, Peshawar - Pakistan \\ ${ }^{2}$ Department of Physiology, Institute of Basic Medical Sciences, KMU, Peshawar - Pakistan
}

\begin{abstract}
Objectives: This study aims to find out whether there is a significant relationship between blood pressure responses due to handgrip $(\mathrm{HG})$ exercise in non-hypertensive young adults, and family history of hypertension.

Material \& Methods: This is a cross-sectional study conducted in Khyber Medical College on healthy students of first and second-year MBBS, after obtaining ethical approval from the institutional ethical committee. 140 (70 males and 70 females) out of 500 students were selected via using a random number generating website. After taking informed consent and history, the students were made to perform the handgrip exercise for 5 minutes at $30 \%$ of their maximum pressure. BP was recorded before during and after the procedure via an electronic BP measuring device. The data was then analyzed using SPSS version 20.0.

Results: There was a significant difference between groups $A$ and $B$ in terms of change in SBP $(\Delta \operatorname{SBP})$ both during $(p=0.024)$ and after $(p=0.033)$ handgrip exercise. The correlation between $30 \%$ of the maximum pressure applied and change in SBP $(\triangle \mathrm{SBP})$ and change in DBP $(\triangle \mathrm{DBP})$ during the application of pressure on handgrip device is significant $(p<0.001)$ in the familial hypertension present group only.

Conclusion: There was a significant change in systolic blood pressure in response to handgrip exercise in the group of subjects with familial hypertension positive. Decline was noted in SBP and DBP during and after the hand grip exercise. This change in systolic and diastolic blood pressure only during HG exercise was positively associated with hand exercise in subjects with history of familial hypertension. In subjects without history of familial hypertension only change in DBP after exercise was positively related $\mathrm{HG}$ exercise. Hence concluded that relation does exist between blood pressure responses to handgrip exercise and familial hypertension.
\end{abstract}

Key Words: Blood pressure; hypertension; family history; isometric exercise; medical students.

This article may be cited as: Zafar U, Rahman SU, Malik O, Salman H. Relationship of blood pressure responses to isometric exercise in non-hypertensive medical students with familial hypertension. J Med Sci 2020 October;28(4):331-336

\section{INTRODUCTION}

An isometric exercise is a form of static exercise in which force is applied against an object, which does not move, and muscle length remains the same (does not decrease). An example is force applied during lifting weights or handgrip exercises. In contrast, isotonic or dynamic exercise is the one in which skeletal muscle length changes when force is exerted. ${ }^{1}$ A handgrip test is a form of isometric exercise. During this type of exercise, the total peripheral resistance increases as a result of increased

\section{Correspondence}

Dr. Umema Zafar

Assistant Professor, Department of Physiology, Khyber

Medical College, Peshawar - Pakistan.

Email: umema.com@gmail.com

Cell: +92-3127788776

Date received: $08-07-2020$

Date revised: $19-10-2020$

Date accepted: $29-11-2020$ sympathetic stimulation, and as a result blood pressure rises.

According to a study conducted in India isometric exercise can be used to diagnose underlying prehypertension in children and young adults with familial hypertension history. ${ }^{2}$

Among the non-modifiable risk factors for hypertension, family history bears the foremost importance. ${ }^{3}$ People with hypertensive parents have an increased probability of developing hypertension. This may also be linked with a deranged metabolic profile or biomarkers of inflammation. ${ }^{4}$ Other theories suggest the following reasons for raised BP: increased sodium reabsorption in proximal tubules of nephrons, high sodium-lithium counter-transport, elevated uric acid level, high fasting plasma insulin concentration, high LDL, oxidative stress and raised body mass index (BMI). ${ }^{3}$ One of the important modifiable factors is a sedentary lifestyle and has a role in the development 
of hypertension. The sedentary lifestyle when combined with familial hypertension, doubles the risk for the development of hypertension. ${ }^{5}$

Recent research in the field suggests that isometric exercise of a particular duration and intensity can reduce average blood pressure, and in particular systolic blood pressure when done on a routine basis. ${ }^{6}$ Another study showed that all forms of exercise; in particular, a combination of dynamic and static exercises resulted in not only weight maintenance but also good blood pressure control. ${ }^{7}$ Majority of studies show that blood pressure both Systolic and diastolic rises momentarily as a result of handgrip test. ${ }^{8}$ Other studies suggest that handgrip test increases afterload and hence total peripheral resistance during the exercise up till a few minutes after exercise, and also increases the Diastolic Blood Pressure (D.B.P) ${ }^{8,9}$

The current study aims to find out whether there is a significant relationship between isometric exercise and blood pressure in non-hypertensive Pakistani young people, and, whether subjects with familial hypertension show a greater rise in BP during the activity.

\section{MATERIALS AND METHODS}

This is a cross-sectional study conducted in the Physiology Department, Khyber Medical College, Peshawar, on students of first years and second-year MBBS. Ethical approval with document number 081/KTH/ERB was obtained from the Ethical Committee of the institute where research was conducted. A total of 140 students without hypertension with ages 19-23 years were included in the study, with a male-female ratio of $1: 1$. This study was conducted from June 2017 to April 2018 and the sampling technique was simple random sampling, the class roll numbers of students were fed in a random number generating website and 140 selected out of 500 students. Students who were taking medications which modified the functions of CVS, having a medical condition such as diabetes mellitus, hypertension, thyroid disorders, cardiac disorders, respiratory diseases, and local hand pathologies and giving a history of smoking were excluded from the study. Relevant clinical and family history was recorded on a predesigned proforma and baseline blood pressure and heart rate were recorded in a sitting posture. Blood pressure and heart rate were recorded using Omron M2 Basic, which fulfills the ESH international protocol, and its 2010 revision requirements. Other baseline parameters such as age height weight were measured and BMI calculated using the WHO formula (weight in $\mathrm{kg}$ / (height in meters2). The subjects were divided into two groups, Group A with any (mother, father) of the hypertensive parents $(n=67)$ and Group B without familial hypertension $(n=73)$. Subjects of both the groups performed the handgrip test with the help of a dynamometer (Model: T.K.K. 5401).

Procedure for performing the Hand Grip Test:
First, the maximum voluntary contraction (MVC) was determined by asking the subject to apply maximum possible pressure to a dynamometer, and then the subject was asked to apply $30 \%$ of MVC and maintain it for 5 minutes with the right hand. Blood pressure was measured in the left arm at rest, during (4 min into the test), and after $1 \mathrm{~min}$ ute of the handgrip test. The left arm was chosen as the right arm was used to apply pressure on the dynamometer, so that would have interfered with the functioning of the B.P apparatus. The participants applied pressure with the dominant hand and their BP was checked on the other hand.

\section{Statistical Analysis:}

The data was analyzed using SPSS version 20 and continuous variables were presented as mean $\pm S D$. Independent sample $t$ test was used to compare mean of SBP and DBP between both groups (with and without history of familial hypertension). Pearson correlation was used to check if Maximum pressure and $30 \%$ of maximum pressure were related to each other. Univariate and multivariate regression analysis were used to check if $30 \%$ of maximum pressure was related to systolic and diastolic blood pressure during and after handgrip exercise. The results of regression analysis were presented as beta coefficient.

$P \leq 0.05$ was considered as significant for analysis in this study.

\section{RESULTS}

Out of the 140 subjects, 70 were males and 70 females. Maximum hand grip pressure and $30 \%$ of maximum pressure and systolic and diastolic blood pressures during and after the handgrip test were almost similar in both the groups. Systolic blood pressure was reduced both during and after the exercise. And the change in SBP (an average fall in SBP) was significant for both during $(p=0.024)$ and after $(p=0.033)$ hand grip exercise in the Group A (table 1). Pearson correlation was done to check if maximum pressure and $30 \%$ of maximum pressure were related with anthropometric and blood pressure values for both the familial hypertension present and absent groups. The maximum pressure and $30 \%$ of max pressure were related with age, height and weight but not related with BMI in both groups.

Considering systolic and diastolic blood pressure during the handgrip exercise test they were only correlated with max pressure and $30 \%$ of max pressure in group A. Systolic blood pressure change after hand grip exercise, was negatively related with max pressure and $30 \%$ of max pressure in group $B(p<0.05$ for both). This relationship was further evaluated in the univariate and multivariate analysis. In the univariate analysis (table 3), age and height were significantly and positively related with $30 \%$ of max pressure in both the groups. However, in multivar- 
RELATIONSHIP OF BLOOD PRESSURE RESPONSES TO ISOMETRIC EXERCISE IN NON-HYPERTENSIVE MEDICAL STUDENTS WITH FAMILIAL HYPERTENSION

iate analysis (table 3), both were related only in the group $B$ and only height was significantly and positively related with $30 \%$ of max pressure in group A. During exercise change in SBP and DBP both were significantly and positively related in group $A$ in both univariate and multivariate analysis after confounding for other variables. However, in group B only change diastolic blood pressure during handgrip test was positively related in the univariate analysis after confounding for other variables. Considering the post exercise SBP and DBP changes there was no relationship in group A. In group B only post exercise SBP change was negatively related, however, this relationship was not significant after confounding for other variables (table 3).

\section{DISCUSSION}

Both groups were almost similar in age, height, weight, and BMI. Baseline systolic and diastolic blood pressure and heart rate were also similar in both the groups. Handgrip strength was also positively correlated with age, height, and weight but not with BMI.

There was a more significant change (fall) in systolic blood pressure during hand grip maneuver in Group A (familial hypertension present) as compared to Group
B (familial hypertension absent). The Pearson correlation and multivariate regression analysis showed that the change in systolic and diastolic blood pressure during the exercise were significantly related in Group A, otherwise, there was no significant relationship in Group B. A study conducted in Jaipur showed elevated sympathetic activity (heart rate variability) in healthy young subjects with hypertensive parents. ${ }^{11}$ This autonomic derangement may lead to the development of hypertension earlier and it can be prevented by lifestyle modifications. ${ }^{11}$ Evidence shows that isometric resistance training usually lowers both SBP and DBP when done long term. ${ }^{12,13} \mathrm{~A}$ systematic review showed that SBP decreased by $80 \%$ in the studies and DBP decreased by $20 \%$ in the studies, following isometric handgrip training. ${ }^{14}$

Blood pressure rises in response to isometric exercise, this is to maintain blood supply to the contracting muscles. This rise in blood pressure is a result of raised cardiac output rather than peripheral vascular resistance unless the patient is diseased. ${ }^{15}$ In young adults, if hypertension if reported it is attributed to raised cardiac output, heart rate, and total peripheral resistance. ${ }^{16}$

Various pathophysiological mechanisms that may lead to the development of hypertension are; cellular salt

Table 1: Descriptive statistics of various parameters in Group A and Group B

\begin{tabular}{|c|c|c|c|}
\hline Parameters & $\begin{array}{c}\text { Group A: Familial } \\
\text { Hypertension present }(n=67)\end{array}$ & $\begin{array}{c}\text { Group B: Familial } \\
\text { Hypertension absent }(n=73)\end{array}$ & $P$ value \\
\hline & Mean \pm SD & Mean \pm SD & \\
\hline Age (years) & $1.14 \pm 19.34$ & $0.91 \pm 19.01$ & 0.059 \\
\hline Height (cm) & $9.28 \pm 166.16$ & $7.97 \pm 168.97$ & 0.057 \\
\hline Weight (kg) & $11.31 \pm 59.46$ & $8.94 \pm 60.53$ & 0.533 \\
\hline BMI & $2.79 \pm 21.56$ & $2.91 \pm 21.47$ & 0.848 \\
\hline Baseline SBP & $14.56 \pm 124.33$ & $14.38 \pm 120.96$ & 0.171 \\
\hline Baseline DBP & $9.36 \pm 81.72$ & $9.82 \pm 78.89$ & 0.084 \\
\hline Baseline HR & $13.58 \pm 88.79$ & $16.23 \pm 88.04$ & 0.768 \\
\hline Max Press applied during HG & $10.14 \pm 30.51$ & $9.57 \pm 31.8$ & 0.440 \\
\hline$\% 30$ of Max Press & $3.03 \pm 9.16$ & $2.87 \pm 9.54$ & 0.446 \\
\hline SBP during HG & $16.58 \pm 119.10$ & $16.74 \pm 119.44$ & 0.906 \\
\hline DBP during $H G$ & $11.59 \pm 79.15$ & $10.64 \pm 78.14$ & 0.591 \\
\hline HR during $H G$ & $12.04 \pm 90.93$ & $13.75 \pm 92.27$ & 0.540 \\
\hline SBP after HG & $16.52 \pm 117.39$ & $15.19 \pm 114.60$ & 0.301 \\
\hline DBP after HG & $11.77 \pm 77.18$ & $10.57 \pm 77.34$ & 0.931 \\
\hline $\mathrm{HR}$ after $\mathrm{HG}$ & $12.13 \pm 88.39$ & $14.86 \pm 90.51$ & 0.36 \\
\hline$\triangle \mathrm{SBP}$ during $\mathrm{HG}$ & $8.89 \pm 5.22-$ & $10.23 \pm 1.52-$ & 0.024 \\
\hline$\triangle \mathrm{DBP}$ during $\mathrm{HG}$ & $6.81 \pm 2.57-$ & $8.33 \pm 0.75-$ & 0.163 \\
\hline$\triangle \mathrm{SBP}$ after $\mathrm{HG}$ & $6.34 \pm 1.72-$ & $10.15 \pm 4.84-$ & 0.033 \\
\hline$\triangle \mathrm{DBP}$ after $\mathrm{HG}$ & $5.58 \pm 1.97$ & $6.59 \pm 0.79$ & 0.259 \\
\hline
\end{tabular}

$\mathrm{HG}=$ Handgrip test, $\mathrm{SBP}=$ Systolic Blood Pressure, $\mathrm{DBP}=$ Diastolic Blood Pressure, $\mathrm{HR}=$ Heart Rate, $\Delta=\mathrm{Change}, \mathrm{Max}=\mathrm{Maximum}$, Press = Pressure, $\triangle \mathrm{SBP}$ during $\mathrm{HG}=$ Baseline SBP- SBP during $\mathrm{HG}, \triangle \mathrm{DBP}$ during $\mathrm{HG}=$ Baseline DBP- $\mathrm{DBP}$ during $\mathrm{HG}, \triangle \mathrm{SBP}$ after $\mathrm{HG}=$ SBP during $H G-S B P$ after $H G, \triangle D B P$ after $H G=D B P$ during $H G-D B P$ after $H G$. 
RELATIONSHIP OF BLOOD PRESSURE RESPONSES TO ISOMETRIC EXERCISE IN NON-HYPERTENSIVE MEDICAL STUDENTS WITH FAMILIAL HYPERTENSION

Table 2: Correlation between pressure applied during HG, baselines and BP changes in terms of $r$ values

\begin{tabular}{|c|c|c|c|c|c|c|c|c|c|c|}
\hline $\begin{array}{l}\text { Study } \\
\text { groups }\end{array}$ & Parameters & $\begin{array}{c}\% 30 \\
\text { of Max } \\
\text { Press }\end{array}$ & $\begin{array}{c}\text { Age } \\
\text { (years) }\end{array}$ & $\begin{array}{l}\text { Height } \\
\text { (cm) }\end{array}$ & $\begin{array}{l}\text { Weight } \\
\text { (kg) }\end{array}$ & BMI & $\Delta \mathrm{SBP}$ & $\triangle \mathrm{DBP}$ & $\Delta 1 \mathrm{SBP}$ & $\triangle 1 D B P$ \\
\hline \multirow{10}{*}{$\begin{array}{l}\text { Group B } \\
(n=73)\end{array}$} & Max Press & $1.000 * *$ & $.414^{\star \star}$ & $.559^{\star \star}$ & $.561^{* *}$ & 0.184 & 0.205 & 0.126 & $-.248^{\star}$ & $0.213-$ \\
\hline & $\begin{array}{c}\% 30 \text { of Max } \\
\text { Press }\end{array}$ & 1 & $.414^{\star *}$ & $.558^{\star *}$ & $.561^{* \star}$ & 0.184 & 0.204 & 0.126 & $-.247^{\star}$ & $0.213-$ \\
\hline & Age (years) & - & 1 & 0.122 & $.272^{\star}$ & 0.195 & 0.004 & $0.106-$ & $0.08-$ & $0.042-$ \\
\hline & Height (cm) & - & - & 1 & $.398^{\star *}$ & $0.196-$ & $0.042-$ & $0.038-$ & 0.073 & 0.195 \\
\hline & Weight (kg) & - & - & - & 1 & $.730^{\star \star *}$ & 0.167 & $0.041-$ & $0.075-$ & 0.098 \\
\hline & BMI & - & - & - & - & 1 & 0.123 & $0.029-$ & $0.096-$ & $0.012-$ \\
\hline & $\triangle \mathrm{SBP}$ & - & - & - & - & - & 1 & $.497^{\star \star *}$ & $-.509 * *$ & $-.298^{*}$ \\
\hline & $\triangle \mathrm{DBP}$ & - & - & - & - & - & - & 1 & $-.409 * \star$ & $-.509 * *$ \\
\hline & $\Delta 1 \mathrm{SBP}$ & - & - & - & - & - & - & - & 1 & $.554^{* *}$ \\
\hline & $\triangle 1 \mathrm{DBP}$ & - & - & - & - & - & - & - & - & 1 \\
\hline \multirow{11}{*}{$\begin{array}{l}\text { Group A } \\
(n=67)\end{array}$} & Parameters & $\begin{array}{c}\% 30 \\
\text { of Max } \\
\text { Press }\end{array}$ & $\begin{array}{c}\text { Age } \\
\text { (years) }\end{array}$ & $\begin{array}{l}\text { Height } \\
\text { (cm) }\end{array}$ & $\begin{array}{c}\text { Weight } \\
\text { (kg) }\end{array}$ & BMI & $\Delta \mathrm{SBP}$ & $\triangle \mathrm{DBP}$ & $\Delta 1 \mathrm{SBP}$ & $\triangle 1 \mathrm{DBP}$ \\
\hline & Max Press & $1.000 * *$ & $.301 *$ & $.601^{* *}$ & $.548^{\star *}$ & 0.193 & $.427^{\star \star}$ & $.453^{\star *}$ & $0.175-$ & $0.076-$ \\
\hline & $\begin{array}{c}\% 30 \text { of Max } \\
\text { Press }\end{array}$ & 1 & $.303^{*}$ & $.599 * \star$ & $.547^{\star *}$ & 0.193 & $.427^{\star \star *}$ & $.449 * *$ & $0.175-$ & $0.075-$ \\
\hline & Age (years) & - & 1 & 0.145 & 0.161 & 0.1 & 0.218 & 0.02 & $-.321^{\star \star}$ & $0.116-$ \\
\hline & Height $(\mathrm{cm})$ & - & - & 1 & $.703^{\star \star}$ & 0.094 & 0.08 & $.251^{*}$ & $0.015-$ & $0.081-$ \\
\hline & Weight (kg) & - & - & - & 1 & $.744^{\star *}$ & 0.089 & 0.14 & $0.1-$ & 0.036 \\
\hline & BMI & - & - & - & - & 1 & 0.072 & $0.03-$ & $0.127-$ & 0.087 \\
\hline & $\Delta \mathrm{SBP}$ & - & - & - & - & - & 1 & $.456^{\star \star}$ & $0.036-$ & $0.021-$ \\
\hline & $\triangle \mathrm{DBP}$ & - & - & - & - & - & - & 1 & 0.019- & $-.406^{\star * *}$ \\
\hline & $\triangle 1 \mathrm{SBP}$ & - & - & - & - & - & - & - & 1 & 0.071 \\
\hline & $\triangle 1 \mathrm{DBP}$ & - & - & - & - & - & - & - & - & 1 \\
\hline
\end{tabular}

** Correlation is significant at the 0.01 level (2-tailed).

* Correlation is significant at the 0.05 level (2-tailed).

$\mathrm{HG}=$ Handgrip test, $\mathrm{SBP}=$ Systolic Blood Pressure, $\mathrm{DBP}=$ Diastolic Blood Pressure, HR= Heart Rate, Max $=$ Maximum, Press $=$ Pressure, $\mathrm{BMI}=$ Body mass index, $\triangle \mathrm{SBP}=$ Change in systolic $\mathrm{BP}$ during handgrip, $\triangle \mathrm{DBP}=$ Change in diastolic $\mathrm{BP}$ during handgrip, $\triangle 1 \mathrm{SBP}=\mathrm{Change}$ in systolic $\mathrm{BP}$ after handgrip, $\triangle 1 \mathrm{DBP}=$ Change in diastolic pressure after handgrip, - sign means that the value is decreasing.

transport mechanisms, renal involvement, cardiovascular morphology and physiology, and cardiovascular reactivity to stress. Muldoon et al revealed that there is strong evidence of left ventricular hypertrophy and altered peripheral vascular responses amongst individuals with a normal B.P and having a positive family history. In contrast, cardiac output, total plasma volume, and cardiovascular responses to isometric exercise and B.P on standing up do not differ in persons with and without familial hypertension. ${ }^{17}$

A study conducted on hypertensive patients showed that there were no uniform acute changes in systolic or diastolic blood pressure. Some subjects showed a rise and some showed a fall in BP. It further points out that the handgrip intensity may be the determining factor for various responses may it be $30 \%, 50 \%$, or maximum. ${ }^{18}$
When an exercise is performed certain tissue metabolites such as lactic acid and adenosine rise, they then activate nerve endings which eventually make sympathetic activity go up. As alpha receptors are activated in peripheral vessels total peripheral resistance rises and B.P goes up. ${ }^{2}$

An experimental trial was conducted in India in which individuals were made to perform 3-min episodes of isometric Handgrip exercise at $30 \%$ of maximum voluntary contraction separated by $5 \mathrm{~min}$ intervals. The exercise was performed 3 times/week for 10 weeks. Blood pressure was measured before and after the exercise. After 10 weeks, both systolic and diastolic blood pressure were noted to have dropped in the majority of the subjects, $(p<0.001)$. 8 This could be attributed to an attenuated sympathetic nerve response which results in a reduction of $B P^{8} A$ fall 
RELATIONSHIP OF BLOOD PRESSURE RESPONSES TO ISOMETRIC EXERCISE IN NON-HYPERTENSIVE MEDICAL STUDENTS WITH FAMILIAL HYPERTENSION

Table 3: Linear regression with $30 \%$ of Maximum pressure as dependent variable

\begin{tabular}{|c|c|c|c|c|c|}
\hline \multirow{2}{*}{ Study groups } & \multirow[t]{2}{*}{ Parameters } & \multicolumn{2}{|c|}{ Univariate } & \multicolumn{2}{|c|}{ Multivariate } \\
\hline & & Beta coefficient & $P$ value & Beta coefficient & $P$ value \\
\hline \multirow{7}{*}{$\begin{array}{l}\text { Group B } \\
(n=73)\end{array}$} & Age (years) & 0.414 & $<0.001$ & 0.272 & 0.002 \\
\hline & Height (cm) & 0.558 & $<0.001$ & 0.632 & $<0.001$ \\
\hline & BMI & 0.184 & 0.120 & 0.232 & 0.007 \\
\hline & $\triangle \mathrm{SBP}$ & 0.204 & 0.084 & 0.105 & 0.297 \\
\hline & $\triangle \mathrm{DBP}$ & 0.126 & $<0.001$ & $0.03-$ & 0.772 \\
\hline & $\triangle 1 \mathrm{SBP}$ & -.247 & 0.035 & $0.056-$ & 0.6 \\
\hline & $\triangle 1 \mathrm{DBP}$ & -.213 & 0.07 & $0.275-$ & 0.011 \\
\hline \multirow{7}{*}{$\begin{array}{l}\text { Group A } \\
(n=67)\end{array}$} & Age (years) & 0.303 & 0.013 & 0.143 & 0.133 \\
\hline & Height $(\mathrm{cm})$ & 0.599 & $<0.001$ & 0.492 & $<0.001$ \\
\hline & $\mathrm{BMI}$ & 0.193 & 0.118 & 0.103 & 0.236 \\
\hline & $\triangle \mathrm{SBP}$ & 0.427 & $<0.001$ & 0.231 & 0.026 \\
\hline & $\triangle \mathrm{DBP}$ & 0.449 & $<0.001$ & 0.255 & 0.025 \\
\hline & $\triangle 1 \mathrm{SBP}$ & -.175 & 0.157 & $0.101-$ & 0.264 \\
\hline & $\triangle 1 \mathrm{DBP}$ & -.075 & 0.548 & 0.088 & 0.362 \\
\hline
\end{tabular}

Dependent Variable: $30 \%$ of Maximum pressure

$\mathrm{BMI}=$ Body mass index, $\triangle \mathrm{SBP}=$ Change in systolic $\mathrm{BP}$ during handgrip, $\triangle \mathrm{DBP}=$ Change in diastolic $\mathrm{BP}$ during handgrip, $\triangle 1 \mathrm{SBP}=\mathrm{Change}$ in systolic $\mathrm{BP}$ after handgrip, $\triangle 1 \mathrm{DBP}=$ Change in diastolic pressure after handgrip

was seen in SBP and DBP during the hand grip exercise in subjects with history of familial hypertension. In subjects without history of familial hypertension only fall in DBP after exercise was positively related to $\mathrm{HG}$ exercise.

Another study conducted in Australia recruited 40 white participants in a randomized trial, the participants conducted four sets of 2-minute handgrip exercise at $30 \%$ of maximum pressure, with 3-minute rest interval between each set. This resulted in a $7 \mathrm{~mm} \mathrm{Hg}$ reduction of systolic blood pressure and a $4 \mathrm{~mm} \mathrm{Hg}$ reduction of mean arterial pressure after eight weeks of exercise training. ${ }^{6}$

The $30 \%$ of maximum hand grip pressure applied was seen to have a significant relation with change in both systolic and diastolic blood pressures during hand grip exercise, after regression analysis was conducted, for the present study. A study conducted by Chao Ji, et al, showed that handgrip strength is positively related to diastolic blood pressure in both the gender groups. ${ }^{19}$ Age, height, and weight in both groups were correlated with handgrip strength in the current study.

Limitations include that this study is focused on the effects of handgrip exercise on blood pressure rather than exploring the pathophysiology behind it. Moreover, it was a cross-sectional study and we did not check the effect of this 5 minutes exercise over time.

\section{CONCLUSION}

It can be concluded that in the group with familial hypertension history there was a significant change in systolic blood pressure in response to handgrip exercise.
An average fall was seen in SBP both during and after handgrip exercise. As far as diastolic blood pressure is concerned it was significantly related to handgrip exercise during performing the test only and that too in familial hypertension present group. Further studies are needed to understand the mechanisms behind these correlations.

\section{REFERENCES}

1. Garg R, Malhotra V, Kumar A, Dhar U, Tripathi Y. Effect of isometric handgrip exercise training on resting blood pressure in normal healthy adults. J Clin Diagnostic Res. 2014;8(9):10-2.

2. Garg R, Malhotra V, Dhar U, Tripathi Y. The isometric handgrip exercise as a test for unmasking hypertension in the offsprings of hypertensive parents. J Clin Diagnostic Res. 2013;7(6):996-9.

3. Ranasinghe P, Cooray DN, Jayawardena R, Katulanda P. The influence of family history of Hypertension on disease prevalence and associated metabolic risk factors among Sri Lankan adults. BMC Public Health. 2015;15(1):576-95.

4. Ciolac EG, Bocchi EA, Bortolotto LA, Carvalho VO, Greve J. Effects of high-intensity aerobic interval training vs moderate exercise on hemodynamic , metabolic and neuro-humoral abnormalities of young normotensive women at high familial risk for hypertension. Hypertens Res. 2010;33(8):836-43.

5. Causes of Secondary Hypertension [Internet]. WebMD. 2017 [cited 2019 Sep 4]. Available from: https:// www.webmd.com/hypertension-high-blood-pres- 
RELATIONSHIP OF BLOOD PRESSURE RESPONSES TO ISOMETRIC EXERCISE IN NON-HYPERTENSIVE MEDICAL STUDENTS WITH FAMILIAL HYPERTENSION

sure/guide/secondary-hypertension-causes\#1

6. Carlson DJ, Inder J, Palanisamy SKA, Mcfarlane JR, Dieberg G, Smart NA. The efficacy of isometric resistance training utilizing handgrip exercise for blood pressure management. Medicine (Baltimore). 2016;95(52):e5791.

7. Mesquita-bastos J, Ribeiro F. Exercise as a tool for hypertension and resistant hypertension management: current insights. Integr Blood Press Control. 2018;11:65-71.

8. Garg R, Malhotra V, Kumar A, Dhar U, Tripathi Y. Effect of Isometric Handgrip Exercise Training on Resting Blood Pressure in Normal Healthy Adults. J Clin Diag Res. 2014;8(9):3-8.

9. Hand Grip maneuver - WikiPedia, the free encyclopedia. In: Wikipedia [Internet]. 2017 [cited 2017 Dec 23]. Available from: https://en.wikipedia.org/wiki/Aspirin

10. Whelton PK, Carey RM, Aronow WS, Casey DE, Collins KJ, Himmelfarb CD, et al. Clinical Practice Guideline 2017 ACC / AHA / AAPA / ABC / ACPM / AGS / APhA / ASH / ASPC / NMA / PCNA Guideline for the Prevention, Detection, Evaluation, and Management of High Blood Pressure in Adults. Hypertension [Internet]. 2018;71(6):13-115. Available from: https://www.ahajournals.org/doi/pdf/10.1161/ HYP.0000000000000065

11. Gupta N, Gupta K, Mathur K. Effect of isometric hand grip on heart rate variability in normotensive healthy offsprings of hypertensive parents. Int J Basic Appl Physiol. 2014;3(1):49-53.

12. Ghadieh AS, Saab B. Evidence for exercise training in the management of hypertension in adults. Can Fam Physician. 2015;61(3):233-9.

13. Taylor K, Coleman DA, Driscoll JO. Ambulatory blood pressure responses to home-based isometric exercise training in pre-hypertensive males. Medicine \& Science in Sports \& Exercise. 2017.

14. Farah $B Q$, Germano-soares $A H$, Rodrigues SLC, Santos CX, Barbosa SS, Vianna LC, et al. Acute and chronic effects of isometric handgrip exercise on cardiovascular variables in hypertensive patients: A systematic review. Sports. 2017;5(55):1-10.
15. Jeelani M, Taklikar $\mathrm{RH}$. Isometric exercise and its effect on blood pressure and heart rate ; a comparative study between healthy, young, and elderly males in and around Raichur city. Int $\mathrm{J}$ Sci Study. 2018;6(1):12-6.

16. Park C, Fraser A, Howe LD, Jones S, Smith GD, Lawlor DA, et al. Elevated Blood Pressure in Adolescence Is Attributable to a Combination of Elevated Cardiac Output and Total Peripheral Resistance. Hypertension. 2018;72(5):1103-8.

17. Muldoon MF, Terrell DF, Bunker CH, Manuck SB. Family history studies in hypertension research review of the literature. Am J Hypertens. 1993;6(1):76-88.

18. Santana IIIFS, Silva GO, Farah IBQ, Germano-soares IIAH, Aluı I, Rodrigues LC, et al. Acute blood pressure responses after different iso-metric handgrip protocols in hypertensive patients. Clinics. 2018;73:e373.

19. Ji C, Zheng L, Zhang R, Wu Q, Zhao Y. Handgrip strength is positively related to blood pressure and hypertension risk: Results from the National Health and nutrition examination survey. Lipids Health Dis. 2018;17(1):86-92.

CONFLICT OF INTEREST: Authors declare no conflict of interest

GRANT SUPPORT AND FINANCIAL DISCLOSURE: NIL

\section{AUTHOR'S CONTRIBUTION}

Following authors have made substantial contributions to the manuscript as under

Zafar U: $\quad$ Concept and design of study, Collection of data, statistcal analysis

Rehman SU: Writting of manuscript, critical review of manuscript

Malik O: $\quad$ Analysis and interpretation of data, statistical analysis

Salman H: Data collection, biblograpy

Authors agree to be accountable for all aspects of the work in ensuring that questions related to the accuracy or integrity of any part of the work are appropriately investigated and resolved. 